\title{
Relationships between rapid urban development and the appropriation of ecosystems in Jiangyin City, Eastern China
}

\author{
Dan $\mathrm{Hu}^{\mathrm{a}, *}$, Shu-li Huang ${ }^{\mathrm{b}}$, Qiang Feng ${ }^{\mathrm{a}}$, Feng $\mathrm{Li}^{\mathrm{a}}$, Juan-juan Zhao ${ }^{\mathrm{a}}$, Yan-hua Zhao ${ }^{\mathrm{a}}$, Ben-nan Wang ${ }^{\mathrm{a}}$ \\ a State Key Lab of Urban \& Regional Ecology, Research Center for Eco-Environmental Sciences, Chinese Academy of Sciences, Beijing 100085, China \\ b Graduate Institute of Urban Planning, National Taipei University, Taipei 10433, Taiwan
}

\section{A R T I C L E I N F O}

\section{Article history:}

Received 1 August 2007

Received in revised form 16 April 2008

Accepted 24 June 2008

Available online 3 August 2008

\section{Keywords:}

Rapid urban development

Dynamic characteristics of ecological footprint

Sustainable resource use

Jiangyin City

Eastern China

\begin{abstract}
A B S T R A C T
The relationships between rapid urban development and its ecological footprint (EF) were investigated for Jiangyin City, in Eastern China. The time-series behaviors of EF in Jiangyin from 1990 to 2005, the characteristics of $\mathrm{EF}$ for the different urbanizing areas within the city, and the quantitative correlations between EF and urban development in Jiangyin were studied. We found: (1) Statistically significant correlations between urban development and $\mathrm{EF}$ (using a power function model and a linear model) showed that the intensity of $\mathrm{EF}$ and the ecological deficit in the city or its sub-areas consistently increased as the city developed, whereas its level of sustainable resource use decreased. (2) Economic development (especially the development of second and tertiary industries) and population growth were the main driving forces for the increase in the city's ecological footprint, whereas a very low bio-capacity and a high requirement to import resources from outside the city were key causes for the decline in the level of sustainable resource use. (3) Jiangyin's development needs must transition towards sustainability, with a moderate city size, urbanization level, and population density, while at the same time, effective actions must be taken to improve or enhance the bio-capacity of the urban-rural landscape.
\end{abstract}

(C) 2008 Elsevier B.V. All rights reserved.

\section{Introduction}

Ecological footprint (EF) analysis is an important approach that can be used to describe human impacts on ecosystems, and since its introduction, it has gradually matured in its concepts and methodology (Vitousek et al., 1986; Haberl et al., 2004; Wackernagel and Rees, 1996; Postel et al., 1996; Wackernagel et al., 1999a,b, 2002).

Ecological footprint analysis has been performed in two main ways: (1) by analysis of the direct appropriation of biophysical quantities (e.g., photosynthetic products) by human activities (Vitousek et al., 1986; Postel et al., 1996; Haberl, 1997), and (2) by analysis of the spatial equivalents of this appropriation of biophysical quantities (Wackernagel and Rees, 1996; Folke et al., 1997; Wackernagel et al., 1999a,b, 2002). In recent years, the analytical methods have been greatly improved by integrating analyses of mass and energy flows into the calculations (Wackernagel et al., 2002; Bicknell et al., 1998; Ferng, 2001; Haberl et al., 2004; Monfreda et al., 2004) and by moving from static analysis at a single point in time to dynamic time-series analysis (Haberl et al., 2001; Wackernagel et al., 2004). As a result, ecological footprint analysis

\footnotetext{
* Corresponding author at: 18 Shuangqing Road, Beijing 100085, China. Tel.: +861062849199.

E-mail addresses: hudan@rcees.ac.cn, hrcees@vip.sina.com (D. Hu).
}

has been successfully applied to analyze the ecological impacts of urban development and to improve urban land use planning (Muñiz and Galindo, 2005; Eaton et al., 2007).

Cities have particularly dramatic influences upon natural ecosystems, and these impacts have become increasingly apparent as the size and number of cities continue to grow and as the intensity and extent of their impacts on ecosystems continue to increase. This is especially true for China, which is currently undergoing unusually rapid urbanization; the urban population has grown from 325 million in 1990 to 342 million in 2003. The number of cities in China has also grown rapidly, from 467 in 1990 to 661 in 2003 , and the population density in cities has also increased, from 279 persons $/ \mathrm{km}^{2}$ in 1990 to 847 persons $/ \mathrm{km}^{2}$ in 2003. (In China, a city is defined as a county-level or larger region with a population that exceeds 100000 , and the establishment of a new city must be approved administratively by the provincial government.) The total area occupied by the built-up portions of cities has grown from $11600 \mathrm{~km}^{2}$ in 1990 to $29000 \mathrm{~km}^{2}$ in 2003 . Simultaneously, the per capita area of roads in these built-up areas has increased from 3.1 to $9.3 \mathrm{~m}^{2}$, and per capita daily domestic use of water has increased from 175.7 to 210.9 L (Ministry of Construction of China, 2003). This rapid development has caused unprecedented impacts on China's ecosystems, and the resulting environmental damage has become a conspicuous characteristic of Chinese urbanization. Thus, understanding the ecological footprint of these rapidly developing cities 
will be crucially important for understanding the impacts of urbanization on ecosystems in China.

Changes in the ecological footprint of rapidly developing cities are complicated, and have dynamic characteristics that depend on the city's location, development model, and growth stage, as well as on the composition, structure, and functions of its surrounding ecosystems. In the present study, we develop several indicators for the intensity, composition, and sustainability of resource use using Jiangyin City, a typical rapidly developing city in Eastern China, as a case study, to examine several priority issues: changes in the dynamic characteristics of the urban ecological footprint over time, differences in the ecological footprint among the city and its subareas (with different levels of urbanization), and the quantitative relationships between the state of urban development and changes in the ecological footprint. Addressing these issues will provide a more precise understanding of the relationships between rapidly developing cities and their surrounding ecosystems and will help to reveal solutions to the problems they face and to improve urban land use planning with the goal of achieving sustainability.

\section{Calculation methods}

The basic calculation procedure used in this study follows the quantitative method for ecological footprints (Wackernagel and Rees, 1996; Wackernagel et al., 1999a,b, 2002). In the present study, we used area-based equivalents of biophysical resources in our analysis.

\subsection{Calculation of ecological demand}

The basic formula for calculating ecological demand (ED, which is also referred to as the ecological footprint, $\mathrm{EF}$ ) is as follows:

$\mathrm{ED}=\sum_{j=1}^{7}\left(Q_{j} \sum_{i=1}^{46}\left(\frac{C_{i}}{P \varphi_{i j}}\right)\right)$

where ED is the per capita ecological footprint (ha person $\left.{ }^{-1} \mathrm{yr}^{-1}\right) ; j$ ( $=1-7$ in the present study) is the type of land being considered; $Q_{j}$ is an equivalence factor for the $j$ th type of land, and represents the ratio of the biological productivity of the $j$ th type of land to the global average biological productivity for all types of bioproductive land, which is dimensionless and equals the average bio-productivity for the seven types of global land included in the present study (Wackernagel and Rees, 1996; Wackernagel et al., 1999a,b, 2002); $C_{i}$ is the total demand for the $i$ th product or service by humans $\left(\mathrm{kg} \mathrm{yr}^{-1}\right) ; i(=1-46$ in the present study) is the number of products being analyzed; $P$ is the total population; and $\varphi_{i j}$ is the global biological yield for the $i$ th product or service provided by the $j$ th type of land ( $\mathrm{kg} / \mathrm{ha}$ ). In this context, "service" means the quantity of the available ecosystem functions available for human purposes (see Section 2.2). As shown in Eq. (1), ED is the product of $Q_{j}$ and per capita consumption in spatial units (equivalent to the quotient of $C_{i}$ and the product of $\varphi_{i j}$ and $P$ ).

\subsection{Calculation of the footprint components}

A basic assumption for calculating the ecological footprint is that the consumption of any resource can be converted into the equivalent amount of bio-productive area required to produce this resource (Wackernagel et al., 1999a,b, 2002). The actual per capita consumption for each type of resource $\left(C_{i}\right)$ equals its production within the city (plus imports and minus exports), divided by its total population $(P)$. The required global area per capita for each type of footprint component is the quotient of $C_{i} / P$ and its global yield $\left(\varphi_{i j}\right)$. For example, per capita consumption of freshwater fish can be converted into a per capita bio-productive area of freshwater divided by the global yield of fish. In the present study, the ecological footprint of Jiangyin consisted of seven main types of components, each of which represents a different (and mutually exclusive) category of demands by the city; in addition, each type of footprint (in global hectares) is the product of the corresponding area of global bio-productive land required by the actual per capita consumption of products and its equivalence factor, and the sum of these footprints equals ED (the per capita ecological footprint) in formula (1).

For the types of consumed products investigated in the present study, the per capita area of bio-productive land required by its production can be calculated as follows:

Area $_{\text {cropland }}=$ per capita actual consumption of agricultural products $(t)$ divided by the average global yield of arable land ( $t / h a)$.

Area $_{\text {pasture }}=$ per capita actual consumption of animal products $(t)$ divided by the average global yield of animal products ( $t / h a)$.

Area $_{\text {freshwater for fish products }}=$ per capita actual consumption of freshwater products $(t)$ divided by the average global yield of freshwater fish products $(\mathrm{t} / \mathrm{ha})$.

Area $_{\text {marine }}=$ per capita actual consumption of sea products $(t)$ divided by the average global yield of sea products ( $t / h a$ ).

The ecological footprint calculates the yield of freshwater fisheries according to their capacity to supply animal protein relative to that of pasture, but excludes the footprint component of aquatic products produced from aquaculture. The yield of world fisheries is $110.9 \mathrm{~kg} / \mathrm{ha}$ for freshwater fisheries and $77.2 \mathrm{~kg} / \mathrm{ha}$ for marine fisheries (Wackernagel et al., 2002).

Area $_{\text {built-up }}=$ per capita actual amount of transformation from agricultural land to built-up area.

This component of the ecological footprint assumes that the built-up area is transformed mostly from prime agricultural land (Wackernagel et al., 1999a,b, 2002).

Area $_{\text {forest }}=$ per capita actual consumption of timber products (mainly roundwood) ( $t$ ) divided by the average global yield of timber products $(\mathrm{t} / \mathrm{ha})$.

The present analysis of Jiangyin's ecological footprint excludes the calculation of the footprint component of freshwater supply because insufficient data is available to provide a useful estimate. Instead, we obtained a preliminary estimate of this component as follows:

Area $_{\text {freshwater supply }}=$ per capita actual consumption of freshwater (t) divided by the average amount of available fresh water per unit of global inland waters ( $\mathrm{t} / \mathrm{ha}$ ).

For example, in 1998, the per capita consumption of freshwater in Jiangyin was around 168.51 tperson $^{-1}$, the total amount of available global fresh water was $4.07 \times 10^{13} \mathrm{~m}^{3}$ (Postel et al., 1996), and the available area of global inland waters was $3.49 \times 10^{8}$ ha (FAO, 2000), thus the area required to supply fresh water to Jiangyin $=168.51 \mathrm{t}_{\text {person }}^{-1} /\left(4.07 \times 10^{13} \mathrm{~m}^{3} / 3.49 \times 10^{8}\right.$ ha $)=1.45 \times$ $10^{-3}$ ha person ${ }^{-1}$. Thus, the footprint component of the city's freshwater supply equaled the product of $1.45 \times 10^{-3}$ ha person ${ }^{-1}$ and its equivalence factor, $5.06 \times 10^{-4}$ ha person ${ }^{-1}$. Obviously, this value was very small and represented a negligible component of the total footprint.

Area $_{\text {fossil energy }}=$ per capita actual consumption of energy products (GJ) divided by the energy conversion constant (GJ/ha).

The energy conversion constant is estimated by calculating the amount of additional forest area needed to sequester the $\mathrm{CO}_{2}$ emissions that result from energy consumption and that could be developed through afforestation; thus, it represents the amount of energy consumption whose $\mathrm{CO}_{2}$ production can be sequestered per unit of additional forest area. The energy conversion constants 
for coal, liquid fossil fuels, natural gas, and hydroelectricity are $55,71,93$, and $1000 \mathrm{GJ} / \mathrm{ha}$, respectively (Wackernagel et al., 1999a, 2002).

\subsection{Calculation of ecological supply}

The basic formula for calculating ecological supply is as follows:

$\mathrm{ES}=\sum_{j=1}^{7}\left(\frac{Q_{j} D_{j} G_{j}}{P}\right) \times(100-12) \%$

where ES is the per capita ecological supply (ha person ${ }^{-1} \mathrm{yr}^{-1}$ ); $Q_{j}$ has the same meaning as in Eq. (1); $D_{j}$ is a yield factor for the $j$ th type of land and represents the ratio of local biological yield of that type of land to the global average biological yield for the $j$ th type of land (Wackernagel et al., 1999a,b, 2002); $G_{j}$ is the total available supply in a given year for the $j$ th type of land (ha); and $P$ is the total population. In the calculation of ES, it is assumed that the yield-adjusted equivalent area is decreased by $12 \%$ to allow for the creation of biodiversity reserves (Wackernagel et al., 1999a,b, 2002). This assumption decreases the calculated values of ES, but creates a significant way to guarantee the sustainability of resource uses in the study area.

\subsection{Calculating the equilibrium between ecological supply and demand}

The balance between supply and demand can be calculated using the following formula:

$\mathrm{PS}=\mathrm{ED}-\mathrm{ES}$

where PS is the per capita ecological deficit $(\mathrm{PS}>0)$, surplus $(\mathrm{PS}<0)$, or equilibrium $(P S=0)$. PS indicates that the magnitude of the ecological footprint for a study area or region relates directly to its available bio-capacity.

\subsection{Equivalence factors}

In the present study, we included seven types of land: land used to provide fossil energy, arable land available for crops, freshwater areas available for aquaculture or to provide tap water, pasture, forest, built-up areas, and marine areas (as defined by Wackernagel, areas that provide food and other services from the sea to humans). The equivalence factors for these types of land use are shown in Table 1.

Various assumptions underlie the calculation of equivalence factors. Most often, human settlement and infrastructure occupy

\section{Table 1}

The equivalence factors used for the seven types of land use included in the present study

\begin{tabular}{lll}
\hline Type of land use & Equivalence factor & Explanation \\
\hline Fossil energy & 1.34 & - \\
$\begin{array}{l}\text { Arable land used for crops } \\
\text { Pasture }\end{array}$ & 2.11 & - \\
& 0.59 & $\begin{array}{l}\text { This is arable land used to } \\
\text { support animals instead of } \\
\text { crops }\end{array}$ \\
Forest & 1.34 & - \\
$\begin{array}{l}\text { Built-up area } \\
\text { Tresh water area used for }\end{array}$ & 2.11 & $\begin{array}{l}\text { This is usually arable land } \\
\text { that has been converted to } \\
\text { aquaculture or tap water }\end{array}$ \\
Marine areas & 0.35 & $\begin{array}{l}\text { non-agricultural uses } \\
-\end{array}$ \\
\hline
\end{tabular}

Source: Wackernagel et al. (2002). highly productive agricultural land, so the ecological footprint analysis assumes that built-up area has the same equivalence factor as the cropland it replaces. Afforestation is one of the best choices for sequestering $\mathrm{CO}_{2}$ emissions from human consumption, so the ecological footprint analysis also assumes that fossil energy land has the same equivalence factor as forest land (Wackernagel et al., 1999a,b).

In practice, there is a diversity of land use such as buildings, infrastructure, gardens, parks, and other open spaces in human built-up areas, some of which are used for bio-productive purposes, but the bio-productivity of built-up areas as a whole is nonetheless much less than that of arable land, so the assumption about its equivalence factor overestimates the equivalent value of its footprint. In addition, there is a diversity of candidates for bioproductive land that provides $\mathrm{CO}_{2}$ sequestration, such as arable, marine, forest, and freshwater areas, which have a mean value of around 1.1 for their equivalence factors (calculated from the data in Table 1); thus, the assumption about the equivalence factor for fossil energy land excludes potential candidates other than forest land, and overestimates the equivalent values of the energy footprint. As a result, energy consumption is often the largest component of the total footprint.

Usually, freshwater areas have a different equivalence factor than marine areas, but the two are nonetheless assumed to have the same value in the ecological footprint method, often leading to underestimation of the freshwater footprint. In addition, the ecological footprint method excludes the footprint component from freshwater aquaculture and freshwater supply, which was estimated in this study using data on the yield of global freshwater capture and its equivalence factor (see Section 2.2). The freshwater supply has the same equivalence factor as that of freshwater capture, so this equivalence factor was used to calculate the footprint of freshwater supply. To calculate the footprint of freshwater aquaculture, the situation was quite different; the yield and equivalence factor of freshwater aquaculture are larger that those of freshwater capture, so the area required for freshwater aquaculture was overestimated, and the freshwater footprint for aquaculture was underestimated. These differences partly or completely offset each other.

In total, the abovementioned assumptions behind the equivalence factors do not balance, and thus distort the actual composition of the total footprint. These distortions are generally acceptable given the difficulties in obtaining data that would allow more accurate calculations.

\subsection{Indicators used for dynamic analysis of the ecological footprint}

In this study, we propose three key aspects that can be used to analyze the dynamic characteristics of the ecological footprint (footprint intensity, composition, and sustainability). For each of these, we developed one to three specific indicators (Table 2).

The intensity of co-option $\left(I_{\mathrm{c}}\right)$ refers to the quantity of co-opted equivalent area per unit of actual area of land within the study area, and usually increases along with the city's development. The larger the value of $I_{\mathrm{c}}$, the more resources are co-opted per unit land in the study area. This indicator represents the spatial intensity of demand that is placed on the bio-capacity of the study area, and if this value exceeds a certain level, the risk to the ecosystem imposed by the urban resource use increases, since the bio-capacity of a study area is usually limited.

The coefficients of the energy component $\left(P_{\mathrm{e}}, \%\right)$ and of the water component $\left(P_{\mathrm{w}}, \%\right)$ refer to the contribution of energy or water appropriation (respectively) to the total ecological footprint (TED) for the study area. Energy and water are two indispensable cate- 
Table 2

Descriptions of the proposed indicators for the ecological footprint analysis in the present study

\begin{tabular}{|c|c|c|}
\hline Indicator & Calculation method & Explanation \\
\hline \multicolumn{3}{|l|}{ Intensity of the footprint } \\
\hline Intensity of co-option ( $I_{\mathrm{c}}$, dimensionless) & $I_{\mathrm{C}}=\mathrm{TED} / A$ & $\begin{array}{l}\text { TED is the total ecological footprint, which } \\
\text { equals the ED multiplied by total population } \\
(P) ; A \text { is the total study area }\end{array}$ \\
\hline \multicolumn{3}{|l|}{ Composition of the footprint } \\
\hline Coefficient of the energy component $\left(P_{\mathrm{e}}, \%\right)$ & $P_{\mathrm{e}}=(\mathrm{EC} / \mathrm{ED}) \times 100 \%$ & $\begin{array}{l}\text { EC is the footprint of energy consumption; ED } \\
\text { is the per capita ecological footprint for the } \\
\text { study area }\end{array}$ \\
\hline Coefficient of the water component $\left(P_{\mathrm{w}}, \%\right)$ & $P_{\mathrm{w}}=(\mathrm{WC} / \mathrm{ED}) \times 100 \%$ & $\begin{array}{l}\text { WC is the consumption footprint for the } \\
\text { freshwater areas; ED is the per capita } \\
\text { ecological footprint for the study area }\end{array}$ \\
\hline \multicolumn{3}{|l|}{ Sustainable resource use } \\
\hline Relative diversity index (RDII) & $\mathrm{RDII}=\left(D_{\mathrm{s}} / D_{\max }\right) \times 100 \%=-\sum_{J}^{N} F(j) \ln F(j) / D_{\max } \times 100 \%$ & $\begin{array}{l}D_{\mathrm{s}} \text { is Shannon's diversity index (Odum, 1971), } \\
D_{\max }=\ln N \text { is the theoretical maximum value } \\
\text { for Shannon's diversity index, and } N \text { is the total } \\
\text { number of types of co-opted land (here, } N=7 \text { ). } \\
F(j) \text { is the proportion of the total land in the } \\
\text { study area accounted for by type } j \text { of co-opted } \\
\text { land }\end{array}$ \\
\hline Net exchange rate (NEX, \%) & $\mathrm{NEX}=(\mathrm{PS} / \mathrm{ED}) \times 100 \%$ & $\begin{array}{l}\text { PS is the per capita ecological balance (which } \\
\text { equals ED minus ES); ED is the per capita } \\
\text { demand (ecological footprint) in the study } \\
\text { area, and ES is the ecological supply }\end{array}$ \\
\hline Sustainable appropriation index (SAI, dimensionless) & $\mathrm{SAI}=\mathrm{RDII} / \mathrm{NEX}$ & $\begin{array}{l}\text { SAI represents the sustainability level of } \\
\text { ecological footprint for the study area }\end{array}$ \\
\hline
\end{tabular}

gories of resource consumption, and energy usually accounts for the biggest proportion of the total footprint. When $P_{\mathrm{e}}$ or $P_{\mathrm{w}}$ increases beyond a certain level, the risk to the ecosystem imposed by the urban resource use increases, since the supplies of energy or water resources within a study area and obtained from outside the area are all limited.

The relative diversity index (RDII) refers to the degree of diversification of the co-opted resources in the study area, with larger RDII values indicating greater diversification of resource use by the study area. For a city or region, increased RDII usually indicates an improvement in resource utilization patterns and a favorable indicator for sustainable urban resource use. The net exchange rate (NEX, \%) refers to the level of dependence of ES upon resources obtained from outside the study area. The smaller this value, the greater the urban self-sufficiency. When a city develops enough to make this value exceed a certain level, the risk to the ecosystem imposed by urban resource use increases, since the bio-capacity of the study area and the supply of resources obtained from outside the area are always limited.

The sustainable appropriation index (SAI, dimensionless) represents the sustainability of resource use by the study area. The larger this value, the greater the sustainability of the study area's resource use. When NEX increases, RDII must also increase to maintain the sustainability of resource use. SAI thus tells us that a good pattern of resource utilization is very important for a given level of resource use, and that it is very important to raise the efficiency of resource use as the resource use increases.

\subsection{Data sources and their reliability}

The calculation of ecological footprint requires large amounts of data on human consumption, population, and land use. In this study, the primary consumption and population data were obtained from the 1991 to 2006 Jiangyin Statistical Yearbooks (Jiangyin Statistical Bureau, 1991-2006), as well as from the results of annual surveys of $1 \%$ of the households in urban and rural areas within the city's administrative boundaries, provided by the Jiangyin Statistical Bureau. The consumption values for the city were categorized mainly into food, non-food plant or animal products, timber, freshwater, and energy (Table 3). The data for land use was obtained from the Jiangyin Statistical Yearbook (1991-2006), which compiled data obtained from annual surveys of changes in Jiangyin's land use by the Jiangyin Land Administration. The data for water resources was obtained from the 1991 to 2006 water resource reports provided by the Jiangyin Water Conservancy Bureau. The data for timber production was obtained from the 1991 to 2006 annual statistical reports on forestry production produced by the Jiangyin Agricultural and Forestry Bureau.

For the urbanizing areas of Jiangyin, the primary data for consumption in 1998 for both urban and rural areas within the city came from the 1999 Jiangyin Statistical Yearbook (Jiangyin Statistical Bureau, 1999), from which consumption was calculated for the urbanizing areas, and the categories of consumption included food, non-food plant or animal products, timber, freshwater, and energy. The primary land use and population data for all the towns within Jiangyin was obtained from the Jiangyin Land Chorography (JLCCC, 1998) and the 1999 Jiangyin Statistical Yearbook, from which secondary land use and population data for the urbanizing areas was calculated by summing up the land use and populations (respectively) of towns located within the urbanizing areas. In addition, the water resources data was obtained from the 1999 water resource report from the Jiangyin Water Conservancy Bureau and the data for timber production was obtained from the 1999 statistical report on forestry production produced by the Jiangyin Agricultural and Forestry Bureau.

There were inadequate data sources for the emissions of wastes and for some consumption categories such as timber and freshwater for the city or its urbanizing areas, so the calculation of ecological footprints in this study did not include the assimilation of wastes, and the consumption of timber only covered paper products and bamboo, excluding furniture, firewood, and directly used roundwood. The amount of freshwater only covered part of the industrial, agricultural, and domestic usages. This limitation of data availability typically leads to underestimates of the total footprint.

For the data analysis in this study, the calculation results are expressed to a maximum of two decimal places (where possible) 
Table 3

The main categories of resource consumption in Jiangyin City between 1990 and 2005

\begin{tabular}{|c|c|c|c|c|}
\hline Per capita consumption of resources ${ }^{b}$ & Per capita production & $\begin{array}{l}\text { Per capita consumption } \\
\text { of raw materials }\end{array}$ & $\begin{array}{l}\text { Total equivalent of footprint } \\
\text { components (ha person }^{-1} \text { ) }\end{array}$ & Types of co-opted land ${ }^{c}$ \\
\hline \multicolumn{5}{|l|}{1990} \\
\hline Food (kg) & 727.43 & 431.04 & 0.40 & A, P, W, M \\
\hline Timber $\left(\mathrm{m}^{3}\right)$ & $<0.001$ & 0.01 & 0.01 & $\mathrm{~F}$ \\
\hline Non-food plant and animal products (kg) & 0.29 & 9.40 & 0.02 & $A, P, F$ \\
\hline Freshwater $(t)^{d}$ & 115.45 & 87.79 & $<0.01$ & W \\
\hline Energy (GJ) & 0.00 & 34.47 & 0.79 & $\mathrm{E}$ \\
\hline Subtotal & - & - & 1.22 & \\
\hline \multicolumn{5}{|l|}{1995} \\
\hline Food (kg) & 734.53 & 400.95 & 0.41 & A, P, W, M \\
\hline Timber $\left(\mathrm{m}^{3}\right)$ & $<0.001$ & 0.01 & 0.01 & $\mathrm{~F}$ \\
\hline Non-food plant and animal products (kg) & 0.02 & 8.36 & 0.02 & $A, P, F$ \\
\hline Freshwater $(t)^{d}$ & 111.98 & 41.43 & $<0.01$ & $\mathrm{~W}$ \\
\hline Energy (GJ) & 0.00 & 46.26 & 1.07 & $\mathrm{E}$ \\
\hline Subtotal & - & - & 1.50 & \\
\hline \multicolumn{5}{|l|}{2000} \\
\hline Food (kg) & 686.89 & 442.29 & 0.42 & A, P, W, M \\
\hline Timber $\left(\mathrm{m}^{3}\right)$ & $<0.001$ & 0.02 & 0.01 & $\mathrm{~F}$ \\
\hline Non-food plant and animal products (kg) & 177.28 & 11.20 & 0.06 & $A, P, F$ \\
\hline Freshwater $(t)^{d}$ & 484.69 & 647.25 & $<0.01$ & W \\
\hline Energy (GJ) & 0.00 & 73.99 & 1.64 & $\mathrm{E}$ \\
\hline Subtotal & - & - & 2.13 & \\
\hline \multicolumn{5}{|l|}{2002} \\
\hline Food (kg) & 664.92 & 427.02 & 0.42 & $\mathrm{~A}, \mathrm{P}, \mathrm{W}, \mathrm{M}$ \\
\hline Timber $\left(\mathrm{m}^{3}\right)$ & $<0.001$ & 0.02 & 0.01 & $\mathrm{~F}$ \\
\hline Non-food plant and animal products (kg) & 338.19 & 42.85 & 0.05 & $A, P, F$ \\
\hline Freshwater $(t)^{d}$ & 545.90 & 643.89 & $<0.01$ & $\mathrm{~W}$ \\
\hline Energy (GJ) & 0.00 & 91.75 & 2.04 & $\mathrm{E}$ \\
\hline Subtotal & - & - & 2.52 & \\
\hline \multicolumn{5}{|l|}{2005} \\
\hline Food (kg) & 687.48 & 402.02 & 0.44 & $\mathrm{~A}, \mathrm{P}, \mathrm{W}, \mathrm{M}$ \\
\hline Timber $\left(\mathrm{m}^{3}\right)$ & $<0.001$ & 0.04 & 0.02 & $\mathrm{~F}$ \\
\hline Non-food plant and animal products (kg) & 425.02 & 57.30 & 0.16 & A, P, F \\
\hline Freshwater $(t)^{d}$ & 367.26 & 598.97 & $<0.01$ & W \\
\hline Energy (GJ) & 0.00 & 136.02 & 2.94 & $\mathrm{E}$ \\
\hline Subtotal & - & - & 3.57 & \\
\hline
\end{tabular}

a Data sources are described in Section 2.7 of the text.

b "Food" includes animal- and plant-based food products such as beef, mutton, pork, poultry, rabbit meat, milk, cheese, eggs, freshwater food, seafood, wheat and rye, rice,

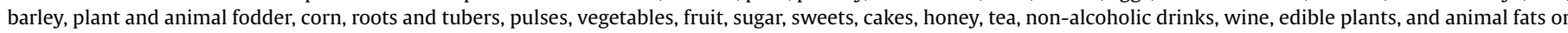

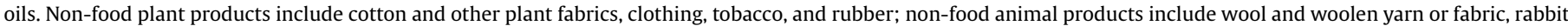
fur, leather, silk, and pearls. Energy includes coal, liquid fossil fuels, natural gas, and electricity.

c The co-opted types of land are: A, arable land; P, pasture; W, freshwater area; M, marine area; F, forest; E, fossil energy land.

$\mathrm{d}$ The freshwater production value was the amount available within the city, excluding the amount from the Yangtze River; the footprint equivalent of freshwater use was less than 0.01 , so it was considered to be a negligible part of the total footprint.

and all percentages were rounded to a maximum of one decimal place.

\section{The temporal and spatial characteristics of Jiangyin City's ecological footprint}

\subsection{Brief introduction to Jiangyin}

Jiangyin is located in Eastern China's Jiangsu Province ( $31^{\circ} 40^{\prime} 34^{\prime}$ to $31^{\circ} 57^{\prime} 36^{\prime \prime} \mathrm{N}, 119^{\circ} 59^{\prime}$ to $120^{\circ} 34^{\prime} 30^{\prime \prime} \mathrm{E}$ ), south of the Yangtze River and north of Taihu Lake (Figs. 1 and 2). Its annual mean temperature is $16.7^{\circ} \mathrm{C}$, and the annual precipitation averages $953.8 \mathrm{~mm}$. According to data provided by the Jiangyin Statistical Bureau, the city's total population was 1.19 million in 2005, divided among 16 towns and 305 administrative villages, with the municipal government located in Chengjiang Town (Fig. 2).
Jiangyin is a rapidly developing city. Its economy is booming, and in the year 2005, its economic strength was rated among the top three county-level cities across the country (Jiangyin Statistical Bureau, 1991-2006). Jiangyin's GDP increased from 4.38 billion RMB in 1990 to 29.09 billion RMB in 2005 (using the 1990 price to calculate inflation-adjusted values). In this paper, all values in RMB have been corrected for inflation using the official values published by the Government of China for each year. The result represents a compound annual rate of increase of $13.5 \%$. During the same period, per capita income increased from 1600 to $4503.11 \mathrm{RMB}$, an increase of about $180 \%$ in total and a linear annual rate of increase of $7.1 \%$. Simultaneously, the population of the city increased from 1.10 million in 1990 to 1.19 million in 2005, the population density increased from 1116 persons $/ \mathrm{km}^{2}$ in 1990 to 1200 persons $/ \mathrm{km}^{2}$ in 2005, and the total area of the built-up portion of the city increased from $148.8 \mathrm{~km}^{2}$ in 1990 to $311.7 \mathrm{~km}^{2}$ in 2005 , while arable 


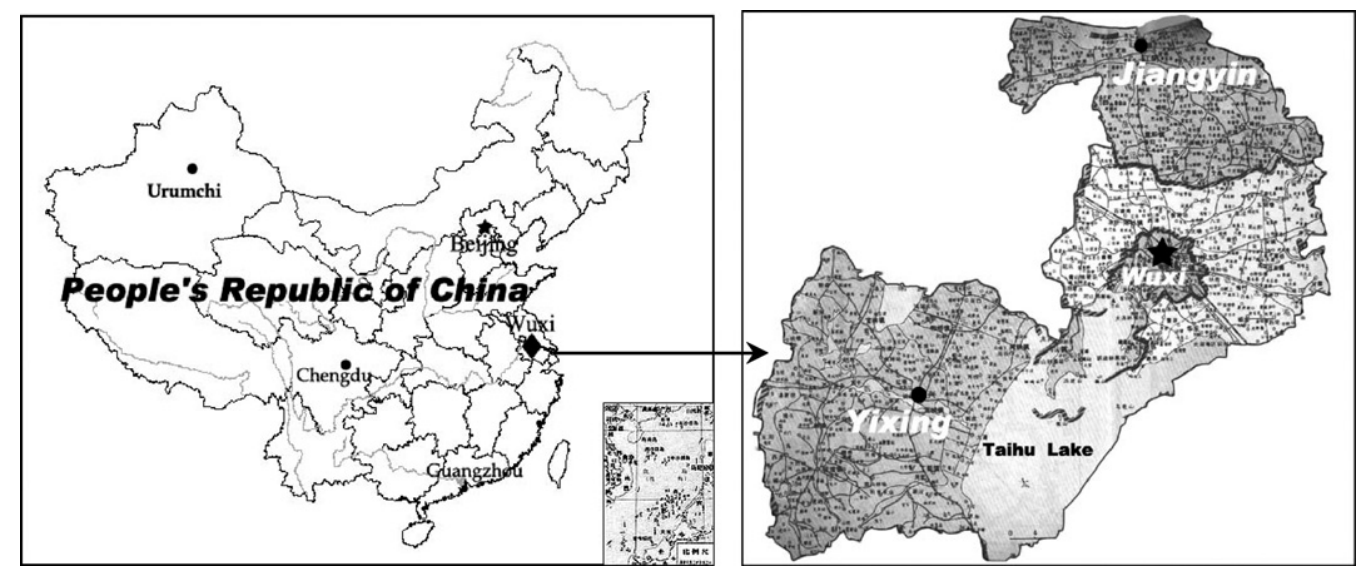

Fig. 1. Location of Jiangyin City in Eastern China.

land decreased from $570.2 \mathrm{~km}^{2}$ in 1990 to $474.7 \mathrm{~km}^{2}$ in 2005 . The city's resource consumption increased even faster than population growth during this period. Per capita water usage increased from 87.8 to $599 \mathrm{~m}^{3}$, and per capita consumption of energy increased from 34.5 to $136 \mathrm{GJ}$ (Jiangyin Statistical Bureau, 1991-2006). The urban growth was accompanied by the development of industrial projects (primarily secondary and tertiary industries) and urban infrastructure to meet the requirements of urban development under the guidance of an urban development plan. However, the local supplies of energy and mineral resources are insufficient to meet the demands of the growing city. Thus, the city depends totally on imports of energy and of raw materials except water (because the city is adjacent to the Yangtze River, and thus has access to abundant water resources). Nonetheless, how to balance Jiangyin's growing urban development with its increasing ecological footprint has become a challenge.

\subsection{Time-series characteristics of Jiangyin's ecological footprint}

As the city developed from 1990 to 2005 , its ecological footprint also increased, and this was characterized by continuous increases in resource consumption and changes in land use. Food, energy, and freshwater became the three biggest types of consumption.
The consumption of food remained relatively stable, and the other categories of consumption grew gradually. The use of energy and freshwater increased very rapidly before 2000, but subsequently, the use of energy continued to rise fast, whereas consumption of freshwater became relatively stable (Table 3 ).

\subsubsection{Per capita demand and supply}

The equations in Section 2 provide estimates of the ecological demand and ecological supply (ES) for Jiangyin in 2005 (Table 4), and their time-series dynamics from 1990 to 2005 are presented in Fig. 3. In 2005, the ED of Jiangyin was 3.63 ha, the ES was only $0.25 \mathrm{ha}$, and the resulting per capita ecological deficit (PS) reached $3.37 \mathrm{ha}$. (Here and elsewhere, we have presented results based on rounded values of the raw data, so not all numbers will add up precisely.)

The time series for ED from 1990 to 2005 shows that ED increased continuously, with a linear annual growth rate of $12.8 \%$; the increase was slower (around 7.6\% per year) from 1990 to 2000, and was faster (13.2\%) from 2000 to 2005, revealing an accelerating increase in ED in recent years. In contrast, ES remained nearly constant. As a result, PS (the per capita ecological deficit) tended to increase in parallel with increasing ED, with annual increases of $8.3 \%$ from 1990 to 2000 and $15.1 \%$ from 2000 to 2005; how-

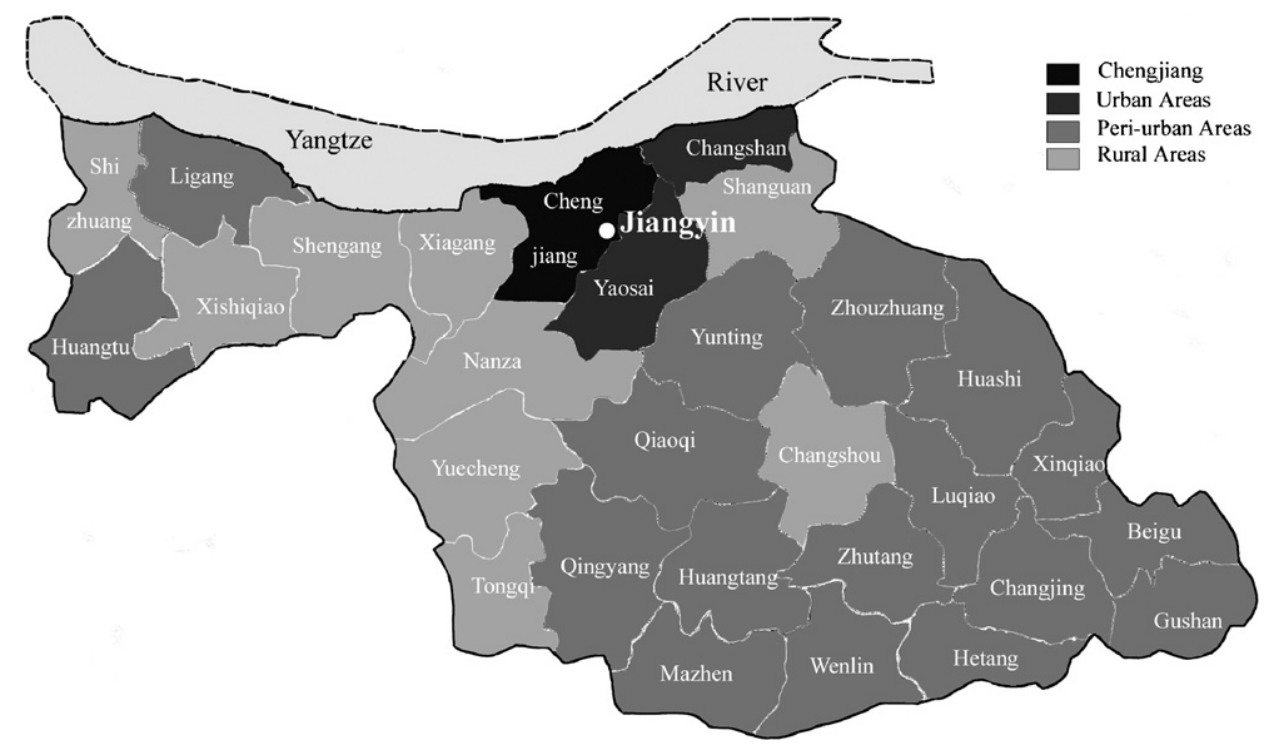

Fig. 2. Spatial pattern of the levels of urbanization in Jiangyin City. 
Table 4

The estimated ecological demand (ED) and ecological supply (ES) for Jiangyin City in $2005^{\text {a }}$

\begin{tabular}{|c|c|c|c|c|c|c|}
\hline \multirow[t]{2}{*}{ Categories of land use } & \multicolumn{3}{|c|}{ ED (ha person ${ }^{-1}$ ) } & \multicolumn{3}{|c|}{ ES (ha person ${ }^{-1}$ ) } \\
\hline & Area & Equivalence factor & Equivalent total area & Area & Yield factor & Yield-adjusted equivalent area \\
\hline Fossil energy & 2.19 & 1.34 & 2.94 & 0.00 & 0.14 & 0.00 \\
\hline Arable land & 0.18 & 2.11 & 0.39 & 0.04 & 1.82 & 0.15 \\
\hline Pasture & 0.27 & 0.59 & 0.16 & $<0.01$ & 4.27 & $<0.01$ \\
\hline Forest & 0.02 & 1.34 & 0.02 & $<0.01$ & 0.14 & $<0.01$ \\
\hline Built-up area & 0.03 & 2.11 & 0.06 & 0.03 & 1.82 & 0.10 \\
\hline Freshwater & 0.16 & 0.35 & 0.05 & 0.01 & 6.27 & 0.03 \\
\hline Marine areas & 0.01 & 0.35 & $<0.01$ & 0.00 & 1.00 & 0.00 \\
\hline $\begin{array}{l}\text { Total } \\
\text { PS }\end{array}$ & \multicolumn{3}{|c|}{$3.63^{b}$} & \multicolumn{2}{|c|}{$\begin{array}{l}\text { Total available (minus } 12 \% \text { for biodiversity) } \\
3.37^{\mathrm{b}}\end{array}$} & $0.25^{\mathrm{b}}$ \\
\hline
\end{tabular}

a ED and ES were calculated according to Eqs. (1) and (2), respectively, in the text.

b The results are rounded to two decimal places.

c The yield-adjusted equivalent area has been decreased by $12 \%$ to allow for legally mandated biodiversity reserves set aside by the city (Wackernagel et al., 1999a,b, 2002).

ever, the rate of increase in the deficit was greater than the rate of increase in the demand (Fig. 3). In addition, food and energy became the two largest components of the ecological footprint, and growth of the energy component was much faster than that of the other components (Table 3 ).

Compared to the results of an ecological footprint analysis for China (Li and Xue, 2006; Zhong et al., 2006), Jiangyin's ED in 1990 was nearly the same as that of China (around 1.2 ha), but after 1995, it increased much faster than that of China, with a rate of increase of $10.8 \%$, versus only $3.5 \%$ for China (Fig. 3 ). This result shows that the rapid development of Jiangyin caused its ED to increase much faster than that of China.

\subsubsection{Dynamics of the components of Jiangyin's ecological footprint}

$P_{\mathrm{e}}$ accounted for an important share of the energy (typically, greater than 60\%) within Jiangyin's ED. From 1990 to 2005, $P_{\mathrm{e}}$ increased at an annual linear rate of $1.8 \%$ from the lowest value of $P_{\mathrm{e}}$, which occurred in 1990 (63.7\%), and this trend indicates that the proportion of the energy component of the city's ED has steadily increased (Table 5), now exceeding the sum of the other components of the ecological footprint accounted for by resource use.

Jiangyin has a high abundance of water resources because there is a high level of rainfall (about $1000 \mathrm{~mm}$ annually), and because the Yangtze River (the largest river in China) runs through its territory, meeting its demand for fresh water. Thus, in contrast with $P_{\mathrm{e}}$, which dominated PS from 1990 to $2005, P_{\mathrm{w}}$ accounted for only a small proportion of ED (a maximum of $3.4 \%$ at its peak, in 2000). From 1990 to $2000, P_{\mathrm{w}}$ increased at a linear annual rate of $20 \%$ as urban devel-

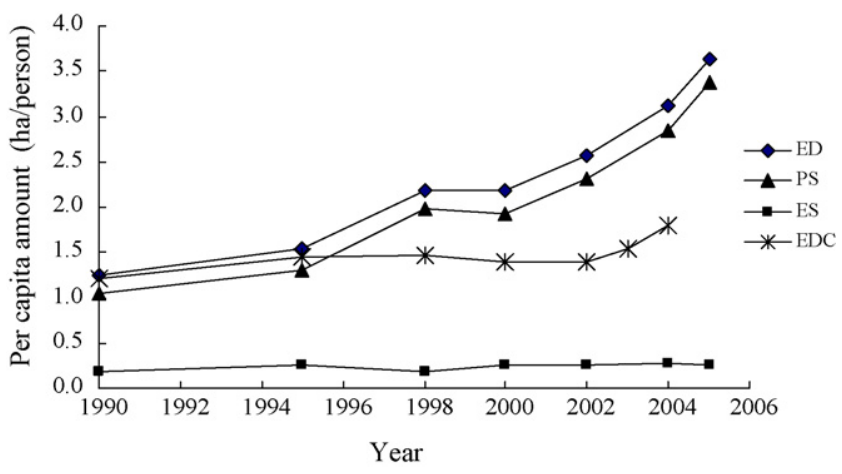

Fig. 3. Temporal changes in the ecological footprint of Jiangyin City from 1990 to 2005 (ED, ecological demand; ES, ecological supply; PS, ecological balance; EDC, ecological demand for China). opment rapidly increased its demand for freshwater (Table 5), but from 2000 to 2005 , it decreased at an annual rate of $11.1 \%$, reaching a $P_{\mathrm{w}}$ value of $1.5 \%$ in 2005 . The reason for the decrease in $P_{\mathrm{w}}$ after 2000 is that many measures for sustainable freshwater management (e.g., water conservation, industrial recycling of freshwater) were implemented to improve the efficiency of freshwater use, and these measures helped to stabilize urban freshwater use.

\subsubsection{Dynamics of spatial intensity of the ecological footprint $\left(I_{c}\right)$}

From 1990 to 2005, $I_{C}$ increased steadily and rapidly, with a linear annual increase of 14.3\%; from 1990 to 2000, this rate was $8.4 \%$, but accelerated to $14.2 \%$ from 2000 to 2005 (Table 5). This result suggested that the ecological footprint per unit area of land increased rapidly and that the intensity of Jiangyin's resource use also rose during this period.

\subsubsection{Dynamics of the sustainability of the city's ecological} footprint (NEX, RDII, and SAI)

The indicators of NEX, RDII, and SAI are strongly related to sustainable resource use. From 1990 to 2005, NEX increased slowly, with only minor fluctuations in the rate of increase, from a value of $84.6 \%$ in 1990 to $88 \%$ in 2000 , then rose steadily thereafter to a peak of $93 \%$ in 2005 (Table 5). NEX has thus remained at a high level since 1990, indicating a strong and increasing dependence of the city on outside resources. Despite remaining steady from 1900 to 1995, RDII decreased at a linear annual rate of $1.9 \%$ over the whole study period, and this rate increased to $3.2 \%$ between 1995 and 2000 , and then changed to an increase of $1.2 \%$ from 2000 to 2005 (Table 5). During the 1990s, urban development depended upon a high diversity of urban resource use, after which the city's development concentrated upon the use of several main resources (energy, freshwater, etc.), and only increased its diversity of resource use in

Table 5

The temporal changes in the indicators of the sustainability of Jiangyin City's ecological footprint from 1990 to 2005

\begin{tabular}{lccccc}
\hline Indicator & \multicolumn{5}{l}{ Year } \\
\cline { 2 - 6 } & 1990 & 1995 & 2000 & 2002 & 2005 \\
\hline$P_{\mathrm{e}}$ & 63.7 & 68.9 & 75.2 & 79.6 & 81.2 \\
$P_{\mathrm{w}}$ & 1.1 & 1.9 & 3.4 & 2.8 & 1.5 \\
$\mathrm{NEX}$ & 84.6 & 83.9 & 88.0 & 90.1 & 93.0 \\
$I_{\mathrm{c}}$ & 13.86 & 17.82 & 25.45 & 30.00 & 43.54 \\
$\mathrm{RDII}$ & 79.04 & 80.65 & 54.01 & 52.34 & 57.10 \\
SAI & 0.93 & 0.96 & 0.61 & 0.58 & 0.61 \\
$D_{\mathrm{p}}$ & 11.16 & 11.51 & 11.65 & 11.72 & 12.00 \\
\hline
\end{tabular}

Notes: $P_{\mathrm{e}}(\%)$, energy coefficient; $P_{\mathrm{w}}(\%)$, water coefficient; NEX(\%), net exchange with surrounding ecosystems; $I_{\mathrm{c}}$ (ha ha ${ }^{-1}$ ), intensity of co-option; RDII, relative diversity index; SAI, sustainable appropriation index; $D_{\mathrm{p}}$ (persons ha ${ }^{-1}$ ), population density. 
Table 6

Urbanization levels in Jiangyin City in 1998

\begin{tabular}{lccl}
\hline & Total area (ha) & $\begin{array}{l}\text { Total population } \\
(\times 10000)\end{array}$ & $\begin{array}{l}\text { Urbanization } \\
\text { level }(\%)^{\mathrm{a}}\end{array}$ \\
\hline Urban $^{\mathrm{b}}$ & 10643 & 22.03 & 64.6 \\
Rural & 27083 & 31.03 & 15.8 \\
Peri-urban & 61105 & 61.37 & 24.1 \\
Chengjiang Town $^{\text {jiangyin City }}$ & 4712 & 14.85 & 77.3 \\
\hline
\end{tabular}

a Urbanization level is defined as the ratio of an area's urban population (the population living in built-up areas) to its total population.

b Including Chengjiang Town.

c Including all administrative districts.

recent years. The increase in the diversity of resource use was beneficial in terms of the sustainability of urban resource use, but the city's resource use remains far less sustainable than its levels at the start of the study period.

From 1990 to 2005, SAI exhibited an overall decrease (despite a small increase between 1990 and 1995), dropping from a high of 0.96 in 1995 to 0.61 in 2005, with a linear annual rate of decrease equal to $2.3 \%$ (Table 5 ). Thus, the level of sustainable urban resource use decreased consistently during this period, and this trend subjects the city to a high risk of increasingly unsustainable ED.

\subsection{Dynamics of the ecological footprint in different parts of Jiangyin and their relationships with levels of urbanization}

It is obvious from observing a city that a range of levels of development exists, and these levels can be represented by indicators such as "urbanization level". In this research, we defined the urbanization level $\left(U_{\mathrm{r}}\right)$ as the ratio of the population living in the built-up part of Jiangyin or its sub-units to the corresponding total population for Jiangyin or a sub-unit of the city (Table 6). This definition was chosen because it is used by all Chinese government statistical agencies, and thus related directly to the data we obtained from these agencies. In this study, the city was categorized into three levels of urbanization (urban, peri-urban, and rural) to allow an examination of the characteristics of ecological footprint for locations within the city that had different developmental levels. Using the available data from 1998, the location and characteristics of these three urbanization levels are shown in Fig. 2 and Table 6.

The "urban" category refers to the principal part or central area of a city that is managed directly by the municipal government, with a very high level of development and a relatively high level of urban infrastructure development. In 1998, the urban area had an urbanization level of $64.6 \%$. The "peri-urban" category refers to a transitional area between the urban area and the rural area of the city. We defined this category as a region where the urbanization level is greater than $20 \%$ but less than the value for the urban area. In 1998 , the peri-urban area had a mean urbanization level of $24.1 \%$. The "rural" category describes regions where the urbanization level
Table 8

Indicators of ecological appropriation by Jiangyin City in 1998 ( $P_{\mathrm{e}}$, energy coefficient: $P_{\mathrm{w}}$, water coefficient; NEX, net exchange with surrounding ecosystems) $)^{\mathrm{a}, \mathrm{b}}$

\begin{tabular}{lllll}
\hline & Urbanization level (\%) & $P_{\mathrm{e}}(\%)$ & $P_{\mathrm{w}}(\%)$ & $\mathrm{NEX}(\%)$ \\
\hline Urban & 64.6 & 85.1 & 0.9 & 97.0 \\
Rural & 15.8 & 40.4 & 3.5 & 80.0 \\
Peri-urban & 24.1 & 67.3 & 2.1 & 85.3 \\
Chengjiang Town & 77.3 & 91.4 & 0.5 & 97.8 \\
Jiangyin City & 29.6 & 65.9 & 2.0 & 91.3 \\
\hline
\end{tabular}

a The primary sources of data for the calculation of these indicators are described in Section 2.7.

b The values of $P_{\mathrm{e}}, P_{\mathrm{w}}$, and NEX were calculated using the equations in Table 2 . For example, $P_{\mathrm{e}}$ of Jiangyin City $=$ ([area of fossil energy $\times$ equivalence factor $] /$ total ecological footprint of the study area $) \times 100 \%=(1.07 \times 1.34 / 2.176) \times 100 \%=65.9 \%$; similarly, NEX for Jiangyin City $=(P S / E D) \times 100 \%=(1.99 / 2.18) \times 100 \%=91.3 \%$.

is lower than or equal to $20 \%$ within the city, and this category had a mean urbanization level of $15.8 \%$ in 1998 . We also examined urbanization for "Jiangyin City", which includes the city's overall administrative territory, and this category had an urbanization level of $29.6 \%$ in 1998 . Chengjiang Town, the seat of the Jiangyin municipal government, has a very high population and a small spatial extent, thus its urbanization level in 1998 reached 77.3\%.

The ecological demand and supply for each of the three levels of urbanization in 1998, as well as for Chengjiang Town and Jiangyin City as a whole, are summarized in Table 7. ED was greatest for Chengjiang Town and the urban area, and least in the rural area. However, the ES values for these three categories were quite different: the maximum ES was observed in the peri-urban area, followed by the rural area, the urban area, and Chengjiang Town. The maximum ecological deficit (PS) was for Chengjiang Town, followed by the urban area, the peri-urban area, and the rural area.

\subsubsection{Differences in the composition of the ecological footprint among the urbanizing areas}

In the various urbanizing areas, the maximum value of $P_{\mathrm{e}}(91.4 \%)$ was for Chengjiang Town, followed by the urban area (85.1\%), the peri-urban area $(67.3 \%)$, and the rural area $(40.4 \%)$ (Table 8$)$. The values of $P_{\mathrm{e}}$ exceeded $65 \%$ for all areas except the rural area, revealing that energy appropriation played a dominant role in the overall ED of areas with a relatively high level of urbanization, and that the higher the urbanization level, the larger the $P_{\mathrm{e}}$ value. Furthermore, the maximum $P_{\mathrm{w}}$ was for the rural area (3.5\%), followed by the peri-urban area (2.1\%), the urban area $(0.9 \%)$, and Chengjiang Town (0.5), which is the opposite of the trend for $P_{\mathrm{e}}$ (Table 8). All $P_{\mathrm{w}}$ values were below $4.0 \%$, indicating that water appropriation is not a dominant component of ED for any of the urbanizing areas of Jiangyin, which is clearly different from the pattern for $P_{\mathrm{e}}$. This result also showed that water consumption in the urbanizing areas did not continue to grow as they developed; water use in the areas with lower urbanization levels accounted for a larger share of their overall footprint, and the higher the urbanization level, the smaller the $P_{\mathrm{w}}$ value.

Table 7

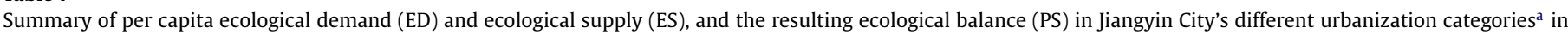
1998

\begin{tabular}{|c|c|c|c|c|}
\hline & Population density (persons ha $\left.\mathrm{a}^{-1}\right)^{\mathrm{b}}$ & ED (ha person ${ }^{-1}$ ) & ES (ha person ${ }^{-1}$ ) & PS (ha person ${ }^{-1}$ ) \\
\hline Urban & 20.70 & 3.98 & 0.12 & 3.86 \\
\hline Rural & 11.46 & 1.13 & 0.23 & 0.90 \\
\hline Peri-urban & 10.04 & 1.82 & 0.27 & 1.56 \\
\hline Chengjiang Town & 31.52 & 4.94 & 0.11 & 4.83 \\
\hline Jiangyin City & 11.58 & 2.18 & 0.19 & 1.99 \\
\hline
\end{tabular}

a The urbanization categories are defined in Table 6 and Fig. 2 .

b In 2005, this indicator changed to 42.79 for Chengjiang, 38.29 for the urban area, 11.46 for the peri-urban area, 7.00 for the rural area, and 12.00 for Jiangyin City (Jiangyin Statistical Bureau, 2006). 
Table 9

Spatial indicators of ecological appropriation for different urbanizing areas of Jiangyin City in 1998 ( $I_{\mathrm{c}}$, intensity of co-option; RDII, relative diversity index; SAI, sustainable appropriation index $)^{\mathrm{a}, \mathrm{b}}$

\begin{tabular}{llcll}
\hline & Urbanization level (\%) & $I_{\mathrm{c}}($ ha ha \\
& (1) & RDII (\%) & SAI $^{\mathrm{c}}$ \\
\hline Urban & 64.6 & 82.32 & 80.1 & 0.83 \\
Rural & 15.8 & 12.94 & 66.7 & 0.83 \\
Peri-urban & 24.1 & 18.32 & 78.1 & 0.92 \\
Chengjiang Town & 77.3 & 155.84 & 71.9 & 0.74 \\
Jiangyin City & 29.6 & 25.20 & 79.3 & 0.87 \\
\hline
\end{tabular}

a The primary sources of data for the calculation of these indicators are described in Section 2.7

b The values of the indicators were calculated using the equations in Table 2 . For example, $I_{\mathrm{c}}$ of Jiangyin City $=(\mathrm{ED} \times$ population of the study area $) /$ the size of the study area $=(2.176 \mathrm{ha} \times 114.44 \times 10000) / 98831 \mathrm{ha}=25.2 \mathrm{ha} \mathrm{ha}^{-1}$; SAI for Jiangyin City $=$ RDII $/$ NEX $=79.3 / 91.3=0.87$.

c The SAI value for the rural area was slightly larger than that of the urban area before rounding.

\subsubsection{Differences in the spatial intensity of the ecological}

footprint for the urbanizing areas

The maximum value of $I_{\mathrm{c}}$ (Table 9) was for Chengjiang Town (155.84ha ha- $\left.{ }^{-1}\right)$, followed by the urban area (82.32 ha ha $\left.{ }^{-1}\right)$, the peri-urban area (18.32 ha ha-1), and the rural area (12.94 ha ha ${ }^{-1}$ ). All $I_{\mathrm{c}}$ values were much larger than the corresponding ecological supply (ES), revealing that all the urbanizing areas required inputs from external ecosystems to sustain their level of ED, and that the higher the urbanization level, the larger the $I_{c}$ value.

\subsubsection{Differences in the sustainability of the ecological footprint \\ (NEX, RDII, and SAI) for the urbanizing areas}

The maximum NEX value (Table 8 ) was for Chengjiang Town (97.8\%), followed by the urban area $(97.0 \%)$, the peri-urban area (85.3\%), and the rural area (80.0\%). All NEX values were thus high ( $80 \%$ or greater), indicating that each urbanizing area had a serious lack of self-sufficiency, that the inputs of resources from outside the areas were high, and that this supply was essential to sustain the ED level of the urbanizing areas. This also reveals that the selfsufficiency of an urbanizing area decreases as its urbanization level increases, and that sub-areas with higher rates of urbanization had greater net exchanges of resources with outside areas.

The maximum value of RDII (Table 9) was for the urban area (80.1\%), followed by the peri-urban area (78.1\%), Chengjiang Town (71.9\%), and the rural area (66.7\%). All RDII values were very high (greater than 60\%), but they did not differ greatly. This result showed that the sub-areas with relatively higher rates of urbanization had a larger diversity of resource use than the rural area, but that RDII did not always increase as the urbanization level increased.

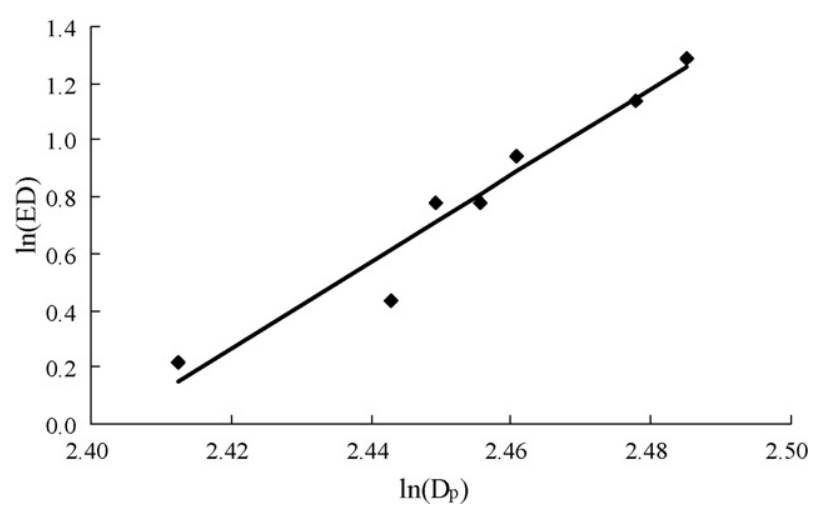

Fig. 4. Results of the linear regression between population density $\left(\ln D_{\mathrm{p}}\right)$ and per capita ecological demand (ln ED) for Jiangyin City from 1990 to 2005.

SAI appears to be strongly and directly correlated with RDII but inversely correlated with NEX. The maximum value of SAI (Table 9) was for the peri-urban area $(0.92)$, followed by the rural area $(0.83)$, the urban area (0.83), and Chengjiang Town (0.74). These values were all close to each other (between 0.7 and 0.9 , to one decimal place), indicating that the sub-areas with a relatively higher diversity of resource use and lower NEX values (or higher self-sufficiency of resources) had a greater capacity for sustainable resource use.

\section{Quantitative relationships between urban development and ecological footprint in Jiangyin}

Population density, urbanization level, and city size are strongly correlated with urban development. Statistical data from many cities around the world has shown that population density, urbanization level, and total population increase as a city grows. Similarly, the population density of Jiangyin grew every year, increasing from $11.16 \mathrm{ha}^{-1}$ in 1990 to $12.00 \mathrm{ha}^{-1}$ in 2005 (Table 5), following the same trend as the city's urbanization level, which increased from $13.6 \%$ in 1990 to $40.8 \%$ in 2005 . The remainder of this section analyzes whether the city's ecological footprint followed a similar trajectory.

\subsection{Urban development $\left(D_{p}\right)$ and the intensity of the ecological footprint (ED)}

From 1990 to 2005, the population density was strongly and significantly correlated with Jiangyin's ED (Table 10). ED increased following a power function as the population density grew (Fig. 4) The more the city developed, the greater its per capita footprint became. This also revealed that at a certain level of population den-

Table 10

The results of linear regressions between the various parameters of Jiangyin City's ecological footprint and its urban development from 1990 to 2005

\begin{tabular}{|c|c|c|}
\hline Indicator of urban development & Regression equation & F-test results ( $95 \%$ confidence level) \\
\hline \multicolumn{3}{|l|}{ Population density $\left(D_{\mathrm{p}}\right)$} \\
\hline ED & $\ln \mathrm{ED}=15.20 \ln D_{\mathrm{p}}-36.53$ & $R^{2}=0.9469(P<0.001)$ \\
\hline NEX & $\ln \mathrm{NEX}=1.35 \ln D_{\mathrm{p}}+1.18$ & $R^{2}=0.6651(P<0.05)$ \\
\hline SAI & $\ln \mathrm{SAI}=-7.44 \ln D_{\mathrm{p}}+17.94$ & $R^{2}=0.6123(P<0.05)$ \\
\hline \multicolumn{3}{|l|}{ Urbanization level $\left(U_{\mathrm{r}}\right)$} \\
\hline$P_{\mathrm{e}}$ & $P_{\mathrm{e}}=0.73 U_{\mathrm{r}}+51.08$ & $R^{2}=0.7664(P<0.01)$ \\
\hline NEX & $\mathrm{NEX}=0.31 U_{\mathrm{r}}+79.41$ & $R^{2}=0.6151(P<0.05)$ \\
\hline SAI & $\mathrm{SAI}=-0.01 U_{\mathrm{r}}+1.20$ & $R^{2}=0.5869(P<0.05)$ \\
\hline \multicolumn{3}{|l|}{ City size (population, $P$ ) } \\
\hline$P$ & $\ln \mathrm{TED}=16.20 \ln P-211.39$ & $R^{2}=0.9529(P<0.001)$ \\
\hline
\end{tabular}

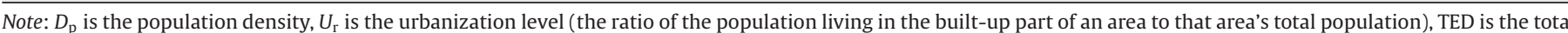
ecological footprint, and $P$ is the total population. 


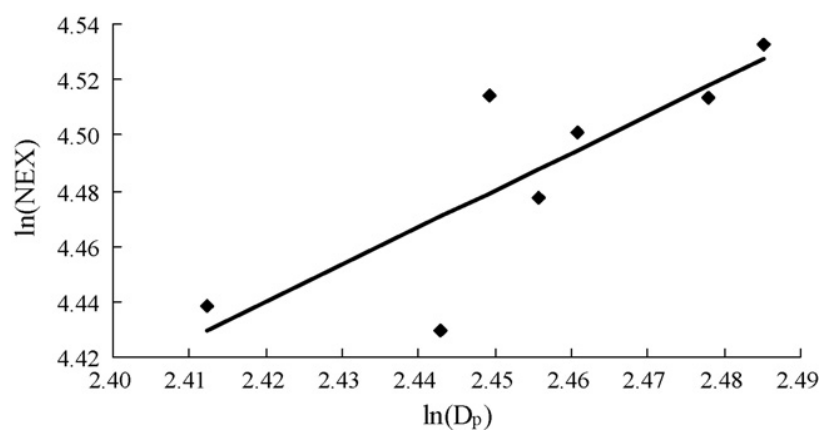

Fig. 5. Results of the linear regression between population density $\left(\ln D_{\mathrm{p}}\right)$ and the net exchange rate (ln NEX) for Jiangyin City from 1990 to 2005.

sity, there are significant impacts on the sustainability of a city's resource use.

\subsection{Urbanization level $\left(U_{r}\right)$ and the energy component of the ecological footprint $\left(P_{e}\right)$}

From 1990 to 2005, the urbanization level was significantly correlated with Jiangyin's $P_{\mathrm{e}}$. This indicated that $P_{\mathrm{e}}$ increased linearly with increasing urbanization level (Table 10). The more the city developed, the greater the proportion of ED accounted for by the energy component. This also revealed that a lower level of urban development is likely to produce more sustainable energy use even when its energy supply comes completely from outside the city, whereas an overly high $P_{\mathrm{e}}$ value creates a high risk of unsustainable energy use.

\subsection{Urban development $\left(D_{p}\right.$ and $U_{r}$ ) and sustainability of the ecological footprint (SAI and NEX)}

Population density and urbanization level were both significantly correlated with NEX and SAI in Jiangyin from 1990 to 2005. The results of this regression indicated that the city's NEX increased and SAI decreased following a power function (for population density) or a linear function (for urbanization level) as the level of urban development increased (Table 10, Figs. 5 and 6). The more the city developed, the greater its NEX value and the lower its SAI value became. This also revealed that lower levels of urban development played a positive role in supporting the city's capacity for sustainable development.

\subsection{City size (total population) and the intensity of the ecological} footprint (ED)

Empirically, a city's size (based on total area or total population) exhibits an obvious correlation with its total resource consump-

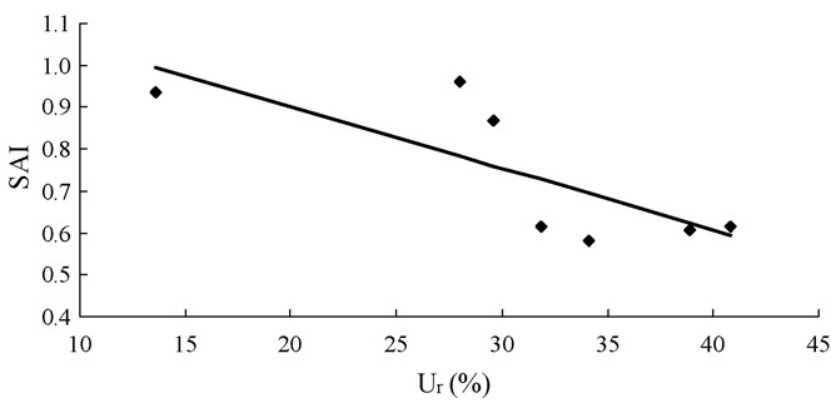

Fig. 6. Results of the linear regression between the urbanization level $\left(U_{\mathrm{r}}\right)$ and the sustainable appropriation index (SAI) for Jiangyin City from 1990 to 2005.

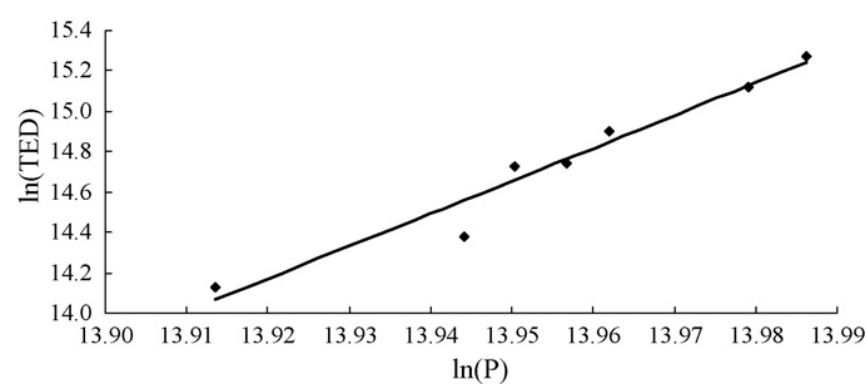

Fig. 7. Results of the linear regression between the total ecological footprint (TED) and the total population $(P)$ on a logarithmic scale (ln TED versus $\ln P$ ) for Jiangyin City from 1990 to 2005.

tion. In the present study, Jiangyin's total ecological footprint was significantly correlated with its total population, following a power function from 1990 to 2005 (Table 10, Fig. 7). This result indicated that the larger the city, the greater its total footprint. Thus, the size of a city is an important factor in determining whether sustainable development is possible.

\section{Discussion}

\subsection{The overall dynamics of Jiangyin's ecological footprint and its} significance for the city's sustainability

The dynamics of Jiangyin's ecological footprint and of its urbanizing areas reflected the changes in the equivalent area required for resource use to maintain or enhance the city's development without compromising its bio-capacity. The analysis in this paper only provided an approximate estimate of the true ecological demand for various resources due to inherent limitations of the study methodology, such as the assumptions underlying the equivalence factors, the inclusion of only some resources that relate to bioproductive areas, and limited availability of data. Nevertheless, the method used in this analysis produced useful, objective results.

The analysis focused on the relationships between urban development (key indicators such as city size, population density, and urbanization level) and its ecological footprint (key indicators in three categories, namely the intensity, composition, and sustainability of the ecological footprint) for Jiangyin and its urbanizing areas. The results indicated that Jiangyin's footprint continuously exceeded its bio-capacity (ED > ES) as its size, population density, and urbanization level rose from 1990 to 2005, and that more and more of the resources required to support this rapid development were obtained from outside the city (as shown by the consistent increase in NEX). The larger the city's size, the greater its total footprint became, and the intensity of resource use also became higher and higher (a continuous growth of $I_{\mathrm{C}}$ ). The energy component of the city's total footprint increased much faster than other components, quickly becoming the dominant component, but the footprints of the food and water components became relatively stable. Furthermore, the sustainability of resource use decreased throughout this period (an overall decline of SAI and RDII). For Jiangyin's urbanizing areas, areas with higher rates of urbanization exhibited a correspondingly higher intensity of resource use, higher percentage of the energy component, lower percentage of the water component, and lower level of sustainable resource use.

The intensity, composition, and sustainability of resource use were three main factors that affected the dynamics of Jiangyin's ecological footprint, and these factors interacted to determine the sustainability of the city's development. Based on the analysis in this paper, Jiangyin had an increasingly high footprint intensity and percentage of the energy component of $\mathrm{ED}$, and a declining 
SAI, which poses an increasingly high risk to the sustainability of its resource use. To permit future sustainable development of the city, planners and managers must aim to achieve a more moderate footprint intensity, a more reasonable composition of the various components of ED, and a higher SAI.

\subsection{Possible causes for the observed trends in the dynamics of ecological footprint during Jiangyin's rapid urban development}

There were obvious correlations between urban development (city size, population density, and urbanization level) and its ecological footprint (intensity, composition, and sustainability of resource use) that resulted from rapid urban development. Since 1990, urban economic development and population growth have been the two leading factors in Jiangyin's rapid urban development. Throughout this period, industrial development dominated the city's economy, and its percentage of the city's GDP decreased slowly, from $65.2 \%$ in 1990 to $61 \%$ in 2005 , while the agricultural sector decreased from $12.7 \%$ in 1990 to $2.0 \%$ in 2005 and tertiary industry increased from $19.0 \%$ in 1990 to $34.3 \%$ in 2005 (Jiangyin Statistical Bureau, 2006). Thus, the development of secondary and tertiary industries became a primary driving force for urban development, leading to corresponding changes in land use and a rapid increase in the amount of built-up area and increasing the demand for resources such as food, water, and energy. Collectively, these changes increased the city's ecological footprint. When the demand was greater than the city's bio-capacity, the city and its urbanizing areas were forced to import resources from outside the city. As a result, the city and its urbanizing areas increased their ecological footprint (revealed by the changes in ED, $P_{\mathrm{e}}, I_{\mathrm{c}}$, and NEX) as it developed (i.e., as its urbanization level increased).

As the city developed, its population also grew, with some people migrating from rural areas into urbanizing areas with a relatively higher rate of urbanization and increasing the population density in these areas (Tables 5 and 7). The change in population thus became another driving force responsible for the increased urban ecological footprint.

Because Jiangyin and its urbanizing areas had a limited biocapacity that could not consistently support its rapid development (Tables 3, 4, 7, and 8), the city and its urbanizing areas depended greatly upon areas outside the city for their supply of resources (especially energy), and the limited availability of these resources increased NEX and decreased RDII, leading to the decline in the city's capacity for sustainable resource use. This suggested that sustainable urban resource use can only be ensured by achieving a more moderate city size, urbanization level, and population density.

\subsection{Methodological issues resulting from this study}

The ecological footprint method is an area-based analysis of human impacts on ecosystems (Wackernagel et al., 1999a,b, 2002, 2004; Monfreda et al., 2004). The reliability and accuracy of such an analysis is subject to the parameters used to calculate ecological footprints, and of these parameters, the equivalence factor is the most important. The equivalence factors used by other researchers (e.g., Loh, 2002) for cropland (2.2), pasture (0.5), forest (1.4), fisheries (freshwater or marine, 0.4), built-up areas (2.2), and fossil energy land (1.4) were slightly higher than those used in the present analysis, except for pasture, because the original data used for the calculation of the latter parameter were different. Thus, the present results differed slightly from those of Loh; for example, for Jiangyin's footprint in 2005, the ED value in the present study equaled 3.63 ha person $^{-1}$, versus a per capita ES of 0.25 ha; in contrast, the calculated values according to Loh's parameters are 3.75 and 0.27 ha, respectively. Although both the latter values were slightly larger than those in the present study, the difference was less than $4 \%$ for demand and $8 \%$ for supply. Another difference was the categories of footprint components included in the analysis; for example, in the present study, the calculation included the consumption of aquatic products from aquaculture and the freshwater supply. The footprint of freshwater use in our calculation represented an additional contribution to the total footprint of less than $0.5 \%$ for Jiangyin and less than $0.1 \%$ for Jiangyin's urbanizing areas.

\section{Conclusions and recommendations}

In this study, three indicators were selected to represent the status of urban development: city size, population density, and urbanization level. In addition, three categories of parameters (the intensity, composition, and sustainability of resource use) were developed to represent the dynamics of the ecological footprint of the city and its urbanizing areas. The quantitative analysis focused on the relationships between rapid urban development and the corresponding ecological footprint.

In Jiangyin, the ecological footprint was significantly correlated with urban development from 1990 to 2005. ED, NEX, $I_{\mathrm{c}}$, and $P_{\mathrm{e}}$ tended to increase, $P_{\mathrm{w}}$, RDII, and SAI tended to decrease, and per capita supply tended to remain stable as the city developed. The ecological footprint varied among the different urbanizing areas in Jiangyin, with $P_{\mathrm{e}}, \mathrm{NEX}$, and RDII higher in the more highly urbanized areas. In contrast, $P_{\mathrm{w}}$ remained at a low level and was not a dominant component of the total footprint. The relationships between three footprint parameters (ED, NEX, and SAI) and population density could be described by power functions, whereas those between three footprint parameters $\left(P_{\mathrm{e}}, \mathrm{NEX}\right.$, and $\left.\mathrm{SAI}\right)$ and urbanization level could be described by a linear function and the total ecological footprint could be described by a power function of the city's size (total population).

Urban development in China is currently in a transition period between rapid growth and sustainable development, thus the sustainability of urban resource use is an important issue Chinese cities must face if they are to find ways to achieve healthy and secure future development. The analysis in this paper revealed that the size, population density, and urbanization level of a city can have decisive impacts on its ecological footprint, with the intensity, composition, and sustainability of resource use closely correlated with changes in urban development that determine the pattern of urban resource use. A sustainable Jiangyin should direct its future urban development towards reaching a moderate city size, urbanization level, and population density, while striving for an appropriate footprint intensity and more sustainable pattern of resource use so that its footprint matches its bio-capacity.

On the basis of this study, urban planners and managers should pay more attention to preserving existing rural areas and placing limits on the level of urbanization in certain areas, especially periurban areas, and should expand the spatial scale of their planning from the urban landscape to an urban-rural landscape so as to better protect or even enhance the city's the bio-capacity. In addition, they should take effective measures to increase the efficiency of the city's resource use and enhance the city's resource recycling and regeneration capacity (including the re-use of wastes) so as to minimize its ecological footprint.

The research in this paper is only preliminary because additional case studies are required to validate the parameters we developed and identify ways to improve and perfect these results, but the analyses nonetheless provide a good starting point for exploring the relationships between rapid urban development and a city's ecological footprint. Future research should address several issues, such as differences in the ecological footprint behaviors of 
cities at different stages of development, the correlations between geographic location and ecological footprint, the dynamic characteristics of ecological footprint during rapid development of central urban areas and its relationships with the peri-urban or rural areas, and the factors that influence these characteristics.

\section{Acknowledgments}

This research was supported by the National Natural Sciences Foundation of China (Grants No. 70573106 and 70433001 ), the National Basic Research Program of China (Grant No. 2005CB724206) and the Knowledge Innovation Project of Chinese Academy of Sciences (KZCX2-YW-324, KZCX2-YW-422).

\section{References}

Bicknell, K.B., Ball, R.J., Cullen, R., Bigsby, H.R., 1998. New methodology for the ecological footprint with an application to the New Zealand economy. Ecological Economics 27, 149-160.

Eaton, R.L., Hammond, G.P., Laurie, J., 2007. Footprints on the landscape: an environmental appraisal of urban and rural living in the developed world. Landscape and Urban Planning 83, 13-28.

FAO UN Food and Agriculture Organization Forestry Department, 2000. Forest Resource Assessment 2000. UN Food and Agriculture Organization, Forestry Department, Rome.

Ferng, J.J., 2001. Using composition of land multiplier to estimate ecological footprints associated with production activity. Ecological Economics 37, 159-172.

Folke, C., Jansson, A., Larsson, J., Costanza, R., 1997. Ecosystems appropriation by cities. Ambio 26 (3), 167-172.

Haberl, H., 1997. Human appropriation of net primary production as an environmental indicator: implications for sustainable development. Ambio 26 (3), 143-146.

Haberl, H., Erb, K.H., Krausmann, F., 2001. How to calculate and interpret ecological footprints for long periods of time: the case of Austria 1926-1995. Ecological Economics 38 (1), 25-45.

Haberl, H., Wackernagel, M., Krausmann, F., Erb, K.H., Monfreda, C., 2004. Ecological footprints and human appropriation of net primary production: a comparison. Land Use Policy 21, 279-288.
Jiangyin Statistical Bureau, 1991-2006. Jiangyin Statistical Yearbook. China Statistics Press, Beijing

Jiangyin Land Chorography Compiling Committee (JLCCC), 1998. Jiangyin Land Chorography. Jiangsu People's Press, Nanjing.

Li, T.S., Xue, N., 2006. Study on the temporal and spatial differences in ecological footprints of China (in Chinese). Journal of China West Normal University 27 (3), $253-255$.

Loh, J. (Ed.), 2002. Living Planet Report 2002. World-Wide Fund for Nature International (WWF), UNEP World Conservation Monitoring Centre, Redefining Progress, Center for Sustainability Studies, Gland, Switzerland.

Muñiz, I., Galindo, A., 2005. Urban form and the ecological footprint of commuting. The case of Barcelona. Ecological Economics 55, 499-514.

Ministry of Construction of China, 2003. China Urban Construction Statistics Yearbook. China Architecture \& Building Press, Beijing.

Monfreda, C., Wackernagel, M., Deumling, D., 2004. Establishing national natural capital accounts based on detailed ecological footprint and biological capacity assessments. Land Use Policy 21, 231-246.

Odum, E.P., 1971. Fundamentals of Ecology, 2nd edition. WB Saunders Company, Philadelphia.

Postel, S.L., Daily, G.C., Ehrlich, P.R., 1996. Human appropriation of renewable fresh water. Science 271, 785-788.

Vitousek, P.M., Ehrlich, P.R., Ehrlich, A.H., Matson, P.A., 1986. Human appropriation of the products of photosynthesis. BioScience 36 (6), 368-373.

Wackernagel, M., Lewan, L., Borgstrom-Hansson, C., 1999a. Evaluating the use of natural capital with the ecological footprint: applications in Sweden and subregions. Ambio 28 (7), 604-612.

Wackernagel, M., Monfreda, C., Schulz, N.B., Erb, K.-H., Haberl, H., Krausmann, F., 2004. Calculating national and global ecological footprint time series: resolving conceptual challenges. Land Use Policy 21, 271-278.

Wackernagel, M., Onisto, L., Bello, P., Callejas Linares, A., López Falfán, I.S., Méndez Garcia, J., Súarez Guerrero, A.I., Súarez Guerrero, M.A., 1999b. National natural capital accounting with the ecological footprint concept. Ecological Economics 29 (3), 375-390.

Wackernagel, M., Rees, W.E., 1996. Our Ecological Footprint: Reducing Human Impact on the Earth. New Society Publishers, Gabriola Island, Philadelphia.

Wackernagel, M., Schulz, N., Deumling, D., Callejas Linares, A., Jenkins, M., Kapos, V. Monfreda, C., Loh, J., Myers, N., Norgaard, R., Randers, J., 2002. Tracking the ecological overshoot of the human economy. Proceedings of the National Academy of Sciences of the USA 99 (14), 9266-9271.

Zhong, X.Q., Zhao, Y.L., Zhong, S., Si, H., 2006. Dynamic analysis on China's ecological footprint demand and supply from 1978 to 2004. Geomatics and Information Science of Wuhan University 31 (11), 1022-1026. 